\title{
Promoción profesional de las mujeres en la negociación colectiva
}

ESMERALDA SANZ BERZAL

Socióloga

Secretaría de Acción Sindical de CCOO

Vocal por CCOO de la Comisión Consultiva Nacional

de Convenios Colectivos

Marzo 2019

doi: https://doi.org/10.20318/femeris.2019.4777

El presente artículo ha sido realizado a partir de una ponencia presentada en el acto institucional que, en conmemoración del 8 de marzo-Día internacional de las mujeres, la Asociación Española de Derecho del Trabajo y de la Seguridad Social celebró conjuntamente con el Consejo Económico y Social, centrado este año en la promoción profesional de las mujeres.

\section{Introducción}

Las grandes movilizaciones que se producen en conmemoración del 8 de marzo nos indican el nivel de inquietud al que la ciudadanía en general, y las mujeres en particular, hemos llegado en relación a la desigualdad entre la vida de mujeres y hombres.

Centrándonos en el ámbito laboral, los medios de comunicación nos ofrecen datos continuos sobre las diferencias entre unas y otros en prácticamente todos los parámetros posibles: tasas de actividad, de desempleo, de temporalidad, de contratación a tiempo parcial no deseada... Y de la brecha salarial como reflejo de la suma de todas las desigualdades.

El mercado de trabajo no es, sin embargo, una realidad al margen del resto de la sociedad sino que, por el contrario, es el espejo en el que evidenciamos las desigualdades que hemos vivido de forma normalizada hasta hace relativamente poco tiempo: las segregaciones horizontal y vertical, directamente asociadas a las desigualdades salariales, sólo producen este efecto porque se sustentan en una infravaloración social del trabajo realizado tradicionalmente por las mujeres que se traduce en la adjudicación de un menor valor añadido

*esanz@ccoo.es 
a las ocupaciones feminizadas; y, por otra parte, la preeminencia masculina en el mundo laboral ha conducido a una supremacía de los factores de valoración asociados con lo masculino frente a la invisibilización de los asociados con las mujeres justificando, con métodos supuestamente empíricos, una segregación vertical que provoca una evidente desigualdad.

Aunque CCOO mantiene un compromiso histórico con la igualdad, nos encontramos en un momento en que consideramos necesario enfatizar aún más nuestras reivindicaciones en pro de la igualdad de género para reducir, cuando no sea posible eliminar, las desigualdades y la discriminación existentes.

Nuestras acciones se agrupan en cuatro frentes fundamentales:

1. La acción sindical en el sentido más amplio de la expresión que abarca desde la participación en cambios normativos, a través del diálogo social, a las movilizaciones, generales o en los centros de trabajo, demandando una sociedad más igualitaria o unas condiciones laborales más justas en las empresas, pasando por demandas canalizadas a través de nuestra participación en los ámbitos institucionales. Una acción sindical que no se limita a la secretaría que ostenta tal condición en el nombre, sino que es transversal en todo el sindicato.

2. A través de la formación sindical sobre igualdad a nuestras y nuestros representantes y, más concretamente, dirigida a quienes participan en las mesas de negociación y centrada en la inclusión de medidas de igualdad en la negociación colectiva (convenios colectivos, planes de igualdad...).

3. Mediante campañas de sensibilización: elaboración y difusión de materiales divulgativos en relación a aspectos tales como la corresponsabilidad, la defensa de un modelo educativo inclusivo; en pro de la eliminación de estereotipos sexistas sobre las profesiones y ocupaciones; o sobre la prevención de la violencia de género, por citar algunos ejemplos.

4. Finalmente, es la negociación colectiva la herramienta con la que una organización sindical puede incidir de forma más directa y específica sobre una realidad laboral que se resiste a la igualdad.

Mi objetivo con este artículo no es relatar los criterios de negociación dirigidos a enfrentar esta cuestión que CCOO elabora cada año sino tratar de ofrecer una visión general, a través de los datos que las estadísticas oficiales sobre negociación colectiva nos brindan, de la involución de las políticas de igualdad en el contenido de los convenios colectivos.

\section{Qué nos dicen las estadísticas sobre la igualdad y la negociación colectiva}

Las estadísticas oficiales sobre negociación colectiva son elaboradas a partir de la información suministrada por quien realiza el registro de los convenios colectivos una vez finalizado el proceso de negociación a través de la cumplimentación de la denominada hoja estadística. 
La última modificación de la hoja estadística de convenios colectivos, coincidente en el tiempo con la puesta en marcha del sistema electrónico de registro (Regcon), se produjo en octubre de 2010 e incorporó una serie de novedades que facilitan en cierta medida un análisis estadístico de la igualdad en la negociación colectiva.

Entre otros cambios:

- Introduce la obligación de registrar una amplia variedad de acuerdos derivados de la negociación colectiva que hasta entonces no eran objeto de registro, entre ellos los planes de igualdad.

- En la Hoja Estadística que se cumplimenta para registrar los convenios colectivos:

- Incorpora un apartado específico dedicado a las Cláusulas sobre Igualdad y no discriminación, que indaga sobre el nivel de desarrollo en los convenios colectivos de las medidas de igualdad promovidas por la Ley Orgánica 3/2007, de 22 de marzo, para la igualdad efectiva de mujeres y hombres.

- Introduce nuevas preguntas en el apartado de tiempo de trabajo relativas a la incorporación de medidas de conciliación.

- Desagrega por sexo los datos relativos al número de trabajadores/as afectados/as, así como a la composición de la mesa de negociación y a las y los firmantes del convenio.

- Además, permite la consulta pública de los acuerdos publicados y de los datos de la hoja estadística correspondiente.

Las estadísticas oficiales de convenios colectivo no se adaptan, sin embargo, para dar entrada a estos nuevos datos hasta 2012 y desafortunadamente, y pese a que la Ley de Igualdad había sido aprobada tres años antes e imponía la obligación de Incluir sistemáticamente la variable de sexo en las estadísticas en el apartado a) de su artículo 20, lo cierto es que en este caso se incumple este precepto y los datos que nos ofrecen son agregados para todas las personas afectadas por los convenios.

Por tanto, los datos que a continuación expongo no son el resultado de un análisis del contenido de los textos convencionales, sino una visión elaborada a partir de las estadísticas anuales sobre convenios colectivos de trabajo publicadas por el Ministerio de Trabajo, Migraciones y Seguridad Social (ECCT del MITRAMISS). Dado que aún no ha sido publicado el avance correspondiente al 2018, el periodo en el que me centraré será aquel del que disponemos de datos: del 2012 al 2017.

\section{Tiempo de trabajo y conciliación}

En el apartado 4 de la hoja estadística, dedicada a Jornada, Vacaciones y Permisos, se han incorporado cuatro nuevas cuestiones relativas a las medidas dirigidas a facilitar la conciliación entre la vida personal, familiar y laboral. 
En primer lugar, se pregunta directamente si existen o no este tipo de medidas y, en caso afirmativo, se incide para esclarecer si éstas se centran en la adaptación o en la reducción de la jornada más allá de lo legalmente establecido.

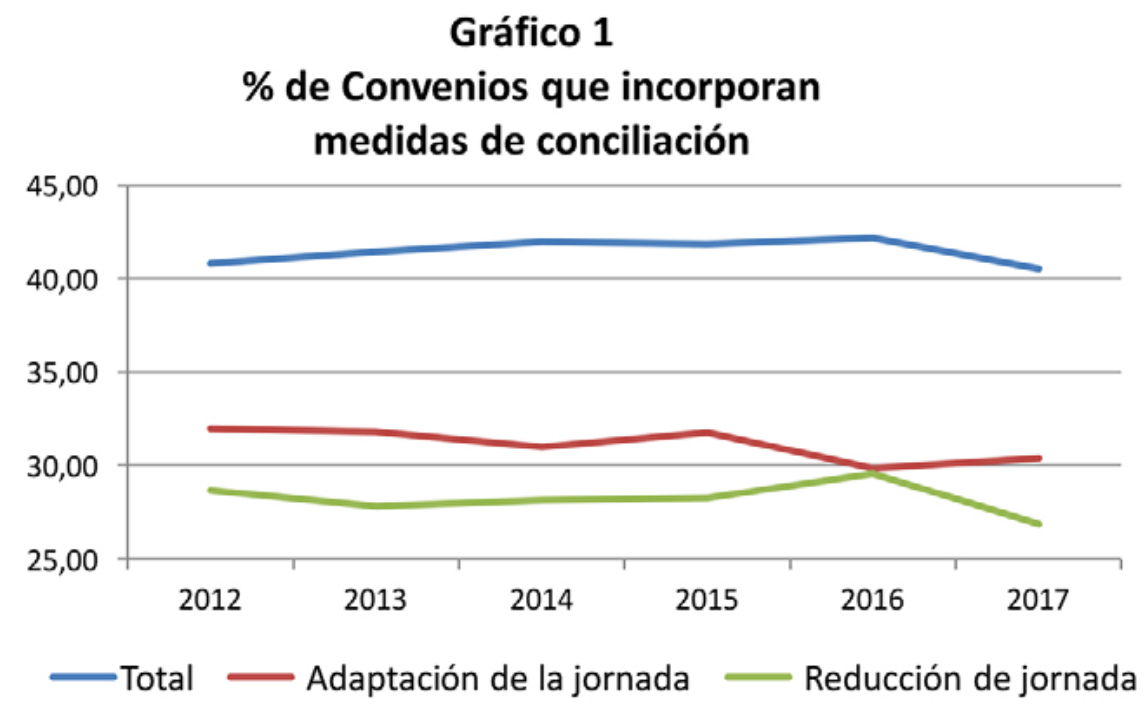

Fuente: Elaboración propia a partir de datos anuales de la ECCT del MITRAMISS.

El gráfico 1 muestra muy pocas variaciones a lo largo del periodo: entre el 40 y el $42 \%$ de los convenios registrados en estos años recogían medidas de este tipo; porcentaje, sin duda, muy importante, si bien la línea general ascendente hasta el 2016 parece quebrarse en 2017 -debemos tener en cuenta que 2017 no es un año estadísticamente cerrado y, por tanto, los datos relativos al mismo pueden verse modificados hasta producirse ese cierre-.

Distinguiendo entre medidas de adaptación o de reducción de la jornada, la línea roja, siempre por encima de la verde, muestra que todos los años son más los convenios que incluyen medidas de adaptación de la jornada que de reducción de la misma, de hecho es la caída de las medidas de reducción de jornada lo que provoca el descenso de la línea general.

Aunque las estadísticas no permiten profundizar más sobre el contenido de estas cláusulas concretas, de la lectura de los textos convencionales y de los estudios publicados al respecto, se deduce que las adaptaciones de jornada se centran, fundamentalmente, en facilitar la flexibilización en el inicio y finalización de la jornada así como, cuando ésta es partida, en flexibilizar también el tiempo de comida. En cuanto a las reducciones de jornada, se dirigen a la ampliación de la edad del menor que da derecho a la reducción de jornada, a la extensión de las personas que generan este derecho, o a la rebaja del mínimo de reducción de jornada establecido legalmente para posibilitar la adaptación de la jornada sin una minoración salarial importante.

Si atendemos a la desagregación por ámbito funcional de los convenios, todas las medidas dirigidas a facilitar la conciliación personal, familiar y laboral, son pactadas en mayor proporción en el ámbito empresarial que en el sectorial, en términos relativos son más los convenios de empresa los que las incorporan que en el ámbito sectorial, si bien 
afectan en términos absolutos a más trabajadores y trabajadoras en el ámbito estatal que en el sectorial.

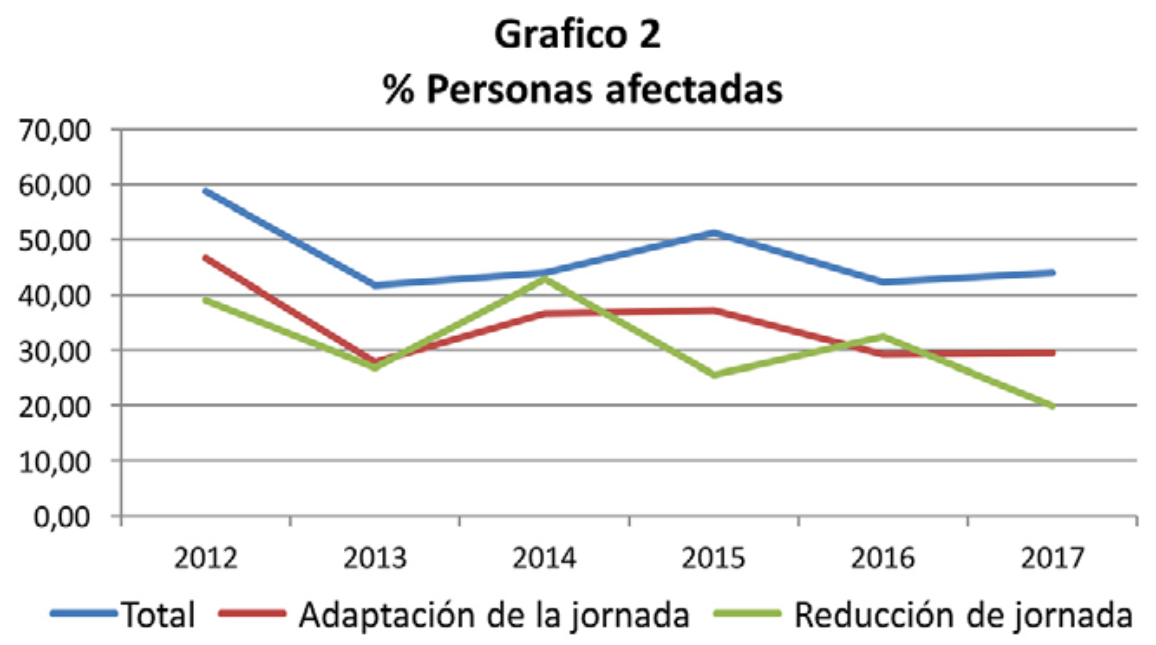

Fuente: Elaboración propia a partir de datos anuales de la ECCT del MITRAMISS.

El gráfico 2, que representa el porcentaje de personas afectadas por estos convenios, refleja el efecto de la mayor inclusión en los convenios de grandes empresas de este tipo de cláusulas, generando líneas más elevas que en el gráfico 1, pero sin distanciarse en exceso, que sería el efecto que provocaría su mayor inserción en los convenios sectoriales.

En segundo lugar, la hoja estadística indaga sobre la regulación de permisos retribuidos por circunstancias familiares o personales que mejoren lo establecido en la legislación vigente, ya sea estableciendo permisos retribuidos no contemplados por la ley o bien ampliando la duración de los que contiene el Estatuto.

Cuadro 1. Permisos retribuidos por circunstancias familiares o personales que mejoren la legislación vigente

\begin{tabular}{|c|c|c|c|c|c|c|}
\hline \multirow{2}{*}{ Año } & \multicolumn{2}{|c|}{ Total (\%) } & \multicolumn{2}{c|}{ Duración de los permisos (\%) } & \multicolumn{2}{c|}{ Inclusión de nuevos permisos (\%) } \\
\cline { 2 - 7 } & Convenios & Trabajadores/as & Convenios & Trabajadores/as & Convenios & Trabajadores/as \\
\hline 2012 & $55,38 \%$ & 57,82 & 49,24 & 44,70 & 37,53 & 36,99 \\
\hline 2013 & 52,78 & 56,25 & 47,74 & 52,66 & 36,19 & 45,35 \\
\hline 2014 & 54,44 & 60,19 & 48,47 & 47,56 & 38,84 & 47,25 \\
\hline 2015 & 54,17 & 74,09 & 49,00 & 68,21 & 39,23 & 64,24 \\
\hline 2016 & 59,75 & 57,27 & 52,30 & 48,05 & 45,07 & 44,80 \\
\hline 2017 & 58,40 & 61,44 & 52,09 & 53,08 & 43,24 & 44,55 \\
\hline
\end{tabular}

Fuente: Elaboración propia a partir de datos anuales de la ECCT del MITRAMISS

El cuadro 1 muestra que a lo largo de todo el periodo, más de la mitad de los convenios, entre el 53\% y el 74\%, dependiendo del año, contienen alguna medida de mejora en el capítulo de permisos retribuidos, siendo más frecuentes las mejoras relativas a la duración de los mis- 
mos que las referentes a la institución de permisos nuevos. Sin duda, la medida más frecuente es la ampliación de los permisos regulados en apartado 3.b) del artículo 37 del Estatuto de los Trabajadores, los referentes a enfermedad, hospitalización, fallecimiento... de familiares.

Pese a que todos los años, y tanto para los convenios de empresa como para los sectoriales, son más los que inciden en la mejora de la duración de los permisos que los que incorporan otros nuevos, resulta sorprendente el elevado número de convenios que incorporan permisos retribuidos diferentes a los legalmente establecidos, los más habituales son los días personales; los permisos para la asistencia a consulta médica propia o para el acompañamiento de personas dependientes -hijos/as o personas mayores-; los permisos para realizar trámites de adopción; o por matrimonio de hijos/as o familiares hasta un determinado grado. Algún convenio, bastante excepcional, se hace eco de otros permisos como, por ejemplo, para asistir a reuniones escolares.

En tercer lugar, la hoja estadística inquiere sobre las mejoras incorporadas en la regulación de la excedencia por cuidado de familiares con respecto a lo regulado en el Estatuto. Se trata, pues, de una cuestión muy genérica, no quedando claro, por ejemplo, si en esta pregunta deben o no incluirse las posibles mejoras a la excedencia por cuidado de hijos dado que el Estatuto de los Trabajadores regula de forma diferenciada y en distintos términos la excedencia por cuidado de hijos/as de la excedencia para el cuidado de un familiar hasta segundo grado.

En cualquier caso, las mejoras podrían ser de muy diverso tipo: alargamiento de los periodos establecidos legalmente, ampliación de los sujetos que pueden generar este derecho (personas con quienes se conviva, por ejemplo, que no sean familiares), dotación de mayor flexibilidad en su disfrute, etc.

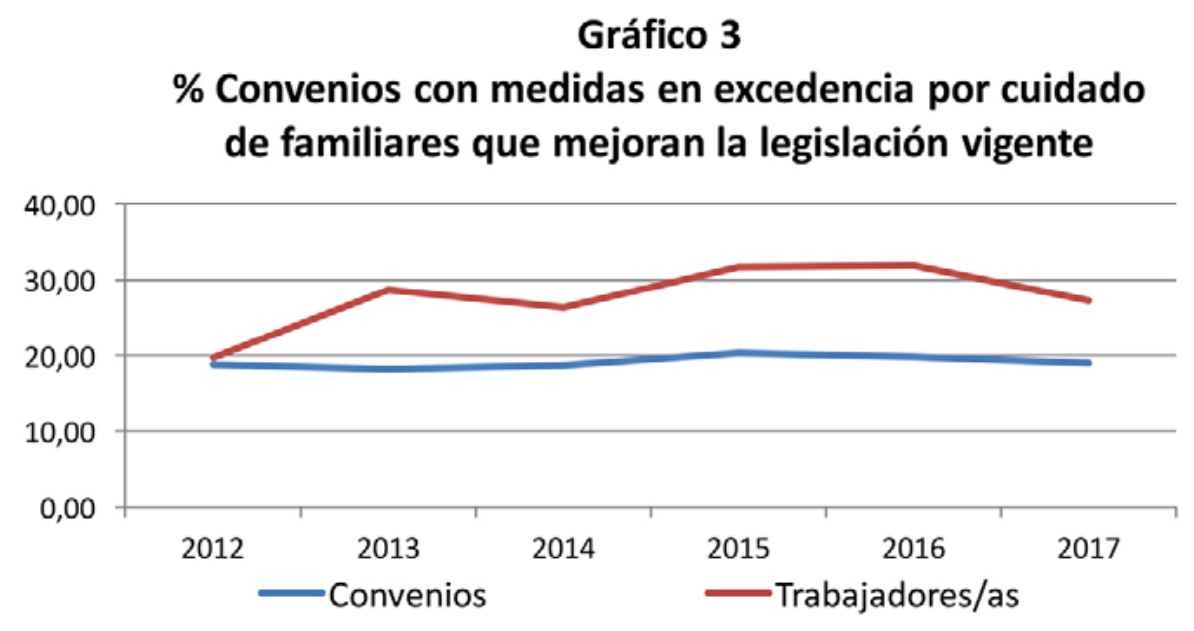

Fuente: Elaboración propia a partir de datos anuales de la ECCT del MITRAMISS.

La línea de evolución es prácticamente plana, la máxima diferencia se produce entre el 18,2\% de convenios que contienen este tipo de mejoras en 2013 y el 20,4 del 2015 . Unos porcentajes, por otra parte, sensiblemente inferiores a los que veíamos en los gráficos anteriores, evidenciando que no son aspectos fáciles de consensuar, sobre todo en los convenios sectoriales. 


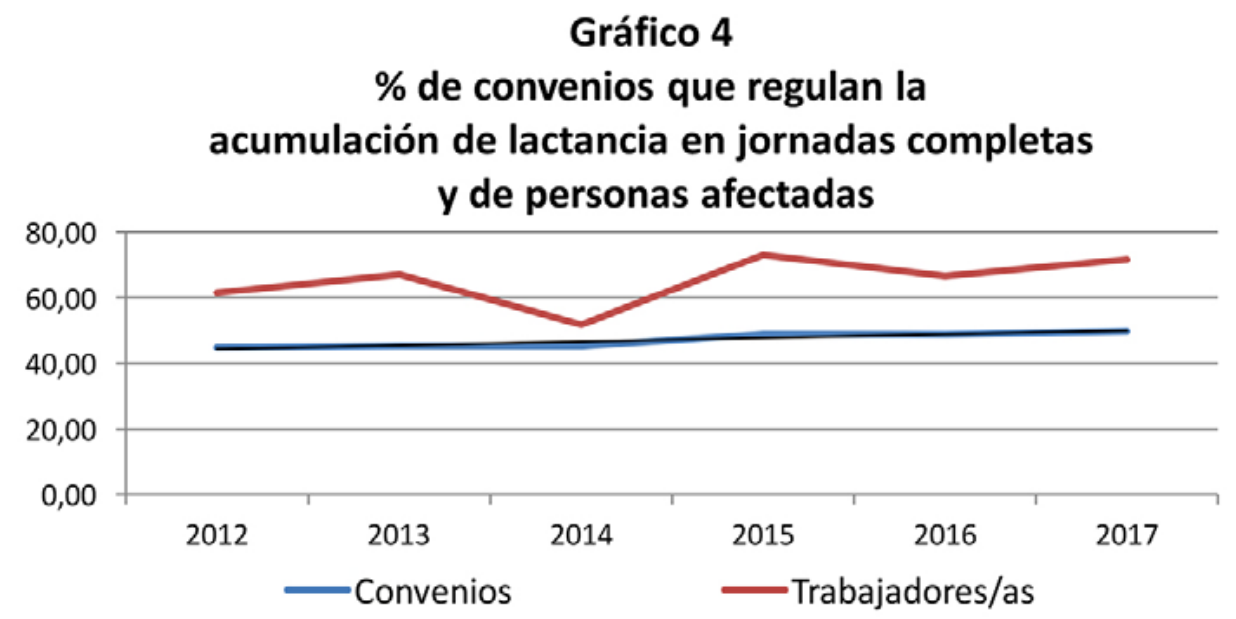

Fuente: Elaboración propia a partir de datos anuales de la ECCT del MITRAMISS.

En relación a la lactancia, la única pregunta que se formula es concretamente si se establece la posibilidad de acumular el derecho a lactancia en jornadas completas. En este punto, debemos recordar que la ley deriva a la negociación colectiva el establecimiento de los términos en que podrá ejercerse el derecho a esta acumulación, si el convenio no lo regula, la ley deriva al acuerdo individual con el empresario. Es evidente que si la representación legal de los y las trabajadoras tiene dificultades para alcanzar un acuerdo en esta materia, mayor dificultad tendrá la trabajadora o el trabajador que deba negociarlo individualmente, por tanto, este es un derecho que difícilmente podrá ejercitarse si los convenios colectivos no lo regulan.

Pues bien, la gráfica revela que entre el 45 y el 50\% de los convenios firmados en estos años establecen la posibilidad de acumular la lactancia. Se trata, sin duda, de un porcentaje muy elevado que cuando menos genera dudas sobre qué implica realmente esta pregunta, sobre cómo es interpretada por quienes registran los convenios.

Es bastante frecuente que los textos convencionales reproduzcan literalmente determinados artículos del Estatuto de los Trabajadores en la idea de que no es necesario nada más para garantizar el cumplimiento del mismo; en este caso, sin embargo, es evidente que si el convenio se limita a copiar los apartados 4 y 5 del artículo 35 del ET, sin establecer claramente en qué se concreta el derecho a acumular la lactancia, el problema quedará sin resolver para quienes deseen ejercer este derecho, pero muy probablemente quien cumplimente la hoja estadística responderá afirmativamente a la pregunta relativa a "la posibilidad" de acumular la lactancia y, evidentemente, la posibilidad siempre existe, pero la facilidad o probabilidad de que tal derecho se ejercite dependerá de cómo esté realmente regulado en el convenio.

Si casi la mitad de los convenios han concretado, por ejemplo, el número de jornadas a las que equivale la acumulación del permiso de lactancia, este porcentaje -sin entrar a valorar la cuantificación concreta de esa acumulación- sería sin duda muy relevante y merecería una valoración muy positiva; pero si resultara que la mayoría de estos convenios se hubieran limitado a reproducir el texto legal, sin ningún tipo de desarrollo, la valoración no sería la misma, ciertamente los datos estadísticos no son suficientes para conocer lo negociado. 


\section{Regulación de los planes de igualdad}

La Ley de Igualdad impone nuevas obligaciones a las empresas y a los responsables de la negociación colectiva, tanto sectorial como de empresa, de cara a lograr la deseada igualdad en el ámbito laboral.

En concreto, y sintetizando mucho: en el ámbito de empresa establece la obligación de negociar un plan de igualdad en aquellas que cuenten con más de doscientas cincuenta personas en plantilla, e invita a las que no llegan a este umbral a negociarlo de forma voluntaria; y, por otra parte, dispone que los convenios sectoriales regulen el modo y las condiciones en que ha de llevarse a cabo la negociación de los planes de igualdad en las empresas incluidas en su ámbito de aplicación, otorgándoles así capacidad para, por ejemplo, rebajar el umbral de los 250 trabajadores/as para las empresas por ellos afectadas.

Dado que la ley establece en esta materia distintas capacidades a los negociadores dependiendo del ámbito funcional de aplicación de los convenios, la hoja estadística incorpora también preguntas distintas dependiendo de si el acuerdo que se registra es de empresa o sectorial.

En la hoja estadística de los convenios de ámbito empresarial se formulan tres preguntas en relación a los planes de igualdad, la primera es si la empresa cuenta, en el momento en que se registra el convenio, con un plan de igualdad o no.

Cuadro 2. Regulación de los Planes de Igualdad en los convenios de empresa.

\begin{tabular}{|c|c|c|c|c|c|}
\hline \multirow{3}{*}{ Año } & \multicolumn{4}{|c|}{ La empresa cuenta con Plan de Igualdad } & \multirow{3}{*}{$\begin{array}{l}\text { Remite a } \\
\text { un acuerdo } \\
\text { futuro (\%) }\end{array}$} \\
\hline & \multicolumn{2}{|c|}{ Total } & \multirow{2}{*}{$\begin{array}{c}\text { En el convenio } \\
(\%)\end{array}$} & \multirow{2}{*}{$\begin{array}{c}\text { En acuerdo } \\
\text { específico (\%) }\end{array}$} & \\
\hline & № de CC & $\%$ & & & \\
\hline 2012 & 337 & 27,20 & 13,24 & 17,51 & 9,52 \\
\hline 2013 & 532 & 28,08 & 14,72 & 17,51 & 10,34 \\
\hline 2014 & 427 & 28,06 & 15,31 & 17,02 & 11,96 \\
\hline 2015 & 372 & 29,13 & 16,05 & 16,99 & 12,45 \\
\hline 2016 & 474 & 31,85 & 15,99 & 20,63 & 10,08 \\
\hline 2017 & 440 & 32,40 & 15,32 & 21,28 & 11,34 \\
\hline
\end{tabular}

Fuente: Elaboración propia a partir de datos anuales de la ECCT del MITRAMISS.

Al cumplimentar la hoja estadística, en un total de 2.582 registros de convenios de ámbito empresarial firmados entre 2012 y 2017 se responde que cuentan con un plan de igualdad, lo que supone entre el 27 y el $32 \%$ del total de los convenios registrados, un porcentaje muy considerable y que no varía mucho entre los diferentes años.

Los porcentajes resultan muy llamativos y también la cifra absoluta. Es cierto que el dato de 2.582 corresponde a registros, lo que supone que algunos convenios han podido ser registrados varias veces a lo largo del periodo $y$, por tanto, varias veces contabilizados los correspondientes planes de igualdad. En cualquier caso, sigue siendo una cifra muy 
alejada de los registrados en el Regcon desde 2010: 279 planes de igualdad de empresas afectadas por convenios colectivos que establezcan la obligación de negociar el plan de igualdad -ya sean de ámbito sectorial o de empresa-, más 66 planes de igualdad para su depósito, hacen un total de 345 planes de igualdad registrados.

Aun considerando que algunos planes de igualdad están contenidos en el propio convenio colectivo y que, por tanto, no son objeto de registro específico; que cabe la posibilidad de que algunos planes que hayan sido firmados antes de la puesta en marcha del registro electrónico, quizás no hayan sido registrados en el mismo; que algunos otros han podido ser registrados erróneamente como acuerdo de otra naturaleza (acuerdos de materias concretas, por ejemplo); o que hay convenios de ámbito inferior a la empresa que pudieran estar afectados por un único plan de igualdad. Aún teniendo en cuenta todos estos factores, hay una distancia enorme entre el número de planes registrados (que también en algunos casos están repetidos, es decir, que responden al segundo o tercer plan de una misma empresa) y las 2.582 empresas que dicen contar con un acuerdo de este tipo.

A quienes respondieron que sí cuentan con un plan de igualdad, la hoja estadística les pregunta si el mismo está regulado en el convenio o en un acuerdo de empresa específico. Esta desagregación nos permite discernir claramente el número de planes de igualdad que, en base a esta información, deberían haber sido registrados como acuerdos específicos en Regcon: 1.621 de los 2.582 responden que son acuerdos específicos y que, por tanto, deberían haber sido registrados.

Por otra parte, si sumamos los porcentajes correspondientes a estas dos columnas, se hace evidente la inconsistencia de estas respuestas: la suma supera el porcentaje total, lo que significa que en algunos casos han sido señaladas ambas opciones de respuesta: que el plan de igualdad está regulado en el convenio y, a la vez, en un acuerdo específico. Ciertamente, cabe la posibilidad de que un plan de igualdad haya sido acordado en primera instancia en un acuerdo específico y, posteriormente, trasladado al convenio de empresa, sin embargo, esta duplicidad podría estar alertando sobre cierta confusión en la interpretación de la pregunta que podría explicar también ese desfase entre lo que estos datos indican y lo que en el registro aparece.

A quienes respondieron que la empresa no contaba con un plan de igualdad, la hoja estadística les pregunta si el convenio remite a un acuerdo futuro de plan de igualdad. Los porcentajes son relativamente bajos en una cuestión fundamental de cara al trabajo sindical de seguimiento de lo que ocurre, por una parte, en las empresas que han contraído el compromiso de negociar un futuro plan de igualdad a fin de garantizar que este compromiso no se quede en una simple manifestación de buenas intenciones; y, por otro lado, en aquellas otras que estando legalmente obligadas a negociar un plan de igualdad, manifiestan no tenerlo y al, menos aparentemente, tampoco tener voluntad de negociarlo en un futuro.

La hoja estadística correspondiente a los convenios sectoriales únicamente contiene dos cuestiones en relación a los planes de igualdad. La primera es de carácter genérico: si se regulan los términos y condiciones en los que se desarrollará el deber de negociar los planes de igualdad a nivel de empresa y, en caso afirmativo, se inquiere por una cuestión 
muy específica: si este deber se establece para empresas con más de 250 trabajadores/as o para empresas de menos de 250 trabajadores/as.

De los convenios sectoriales firmados en este periodo, sólo un porcentaje relativamente bajo (entre el 20 y el 30\% del total), establecen los términos en los que las empresas por ellos afectadas deben negociar los planes de igualdad, bajo este genérico enunciado caben, sin duda, infinidad de situaciones que la hoja estadística no nos permite explorar y que se mueven entre la mera transcripción del texto legal hasta una regulación concisa, detallada y acorde a las especificidades del sector en cuestión, estableciendo, por ejemplo, quién y cómo debe realizar el diagnóstico de situación de partida, cuál es la información mínima y necesaria para tal fin, de qué etapas constará el proceso de negociación, qué plazos deben establecerse para cada una de ellas, cómo se realizará el proceso de implantación de las medidas, y un largo etcétera.

Cuadro 3. Regulación de los Planes de Igualdad en los convenios sectoriales

\begin{tabular}{|c|c|c|c|}
\hline Año & Total & $\begin{array}{c}\text { Para empresas con más } \\
\text { de 250 trabajadores/as (\%) }\end{array}$ & $\begin{array}{c}\text { Para empresas con menos } \\
\text { de 250 trabajadores/as (\%) }\end{array}$ \\
\hline 2012 & 26,39 & 20,53 & 8,21 \\
\hline 2013 & 19,83 & 14,88 & 5,79 \\
\hline 2014 & 20,47 & 16,32 & 6,53 \\
\hline 2015 & 27,96 & 24,01 & 8,51 \\
\hline 2016 & 29,89 & 23,54 & 7,94 \\
\hline 2017 & 28,13 & 21,39 & 8,89 \\
\hline
\end{tabular}

Fuente: Elaboración propia a partir de datos anuales de la ECCT del MITRAMISS

Que sólo un 28\% de los convenios sectoriales firmados en 2017, concreten un aspecto de tanta importancia, transcurridos diez años desde la promulgación de la Ley de Igualdad y cuando ésta deriva la responsabilidad directamente a los convenios sectoriales, parece un porcentaje muy decepcionante. Un aspecto, por otro lado, que si el convenio sectorial no impulsa mediante la correspondiente regulación queda, en gran medida, al libre entendimiento de las partes en cada una de las empresas.

Y de entre los múltiples aspectos que el convenio sectorial puede ordenar, la hoja estadística sólo fija su atención en el tamaño de las empresas obligadas a negociar los planes de igualdad y, más concretamente, en si se amplía o no esta obligación hacia un espectro de empresas de menor tamaño.

Tal y como se desprende del cuadro, la mayoría de los convenios que entran a regular esta materia, mantiene esta obligación para las empresas con plantillas con más de 250 trabajadores/as no añadiendo, por tanto, nada nuevo sobre lo que la ley impone. En cualquier caso, tampoco es desdeñable el porcentaje de los que amplían esta obligación a empresas más pequeñas. 


\section{Medidas por la igualdad}

Al margen de la obligación de negociar un plan de igualdad, la ley obliga a todas las empresas a respetar la igualdad de trato y de oportunidades en el ámbito laboral y, con esta finalidad, les exige la adopción de medidas dirigidas a evitar cualquier tipo de discriminación laboral entre mujeres y hombres, medidas que deberán negociar con la representación legal de los y las trabajadoras.

Esta obligación es general para todas las empresas, independientemente del tamaño y, si bien es cierto que podrían estar insertas en el plan de igualdad en las empresas que cuenten con él, dado que en ningún caso éste debería entrar en contradicción con lo regulado en el convenio colectivo, deberían también quedar reflejadas en el mismo.

Las hojas estadísticas, tanto la de los convenios sectoriales como la de los convenios de empresa, indagan sobre cuatro tipos diferentes de medidas de igualdad:

- dirigidas a promover la igualdad de trato y oportunidades entre mujeres y hombres,

- de preferencia a favor del sexo menos representado (acciones positivas);

- para prevenir el acoso sexual o el acoso por razón de sexo,

- y de protección de las víctimas de violencia de género.

Si se responde afirmativamente a la pregunta genérica sobre la existencia de medidas dirigidas a promover la igualdad, se requiere que se especifique en relación a qué materias se han pactado dichas medidas seleccionando las que correspondan en cada caso entre las opciones que la hoja estadística ofrece.

En cuanto a las medidas de igualdad más genéricas, atendiendo a los datos del cuadro 4 podemos obtener algunas conclusiones: en primer lugar, y a sabiendas de la provisionalidad de la información correspondiente al último año, la tendencia general es positiva para todas y cada una de las materias en los restantes años; y, en segundo lugar, podemos observar que los porcentajes de inclusión de medidas de igualdad por materias se mueven en una horquilla relativamente pequeña para cada uno de los años.

Cuadro 4. \% de Convenios colectivos que incorporan medidas dirigidas a promover la igualdad de trato y oportunidades entre mujeres y hombres

\begin{tabular}{|c|c|c|c|c|c|c|}
\hline Año & Total & Contratación & Formación & Promoción & Salarios & $\begin{array}{c}\text { Estabilidad en } \\
\text { el empleo }\end{array}$ \\
\hline 2012 & 25,89 & 22,34 & 21,20 & 22,15 & 21,46 & 17,53 \\
\hline 2013 & 26,59 & 22,79 & 21,31 & 22,99 & 22,11 & 19,07 \\
\hline 2014 & 28,67 & 25,55 & 22,81 & 24,91 & 23,51 & 20,06 \\
\hline 2015 & 30,64 & 26,90 & 24,16 & 26,21 & 25,09 & 21,17 \\
\hline $\mathbf{2 0 1 6}$ & 33,12 & 28,46 & 25,19 & 27,65 & 25,56 & 20,26 \\
\hline $\mathbf{2 0 1 7}$ & 31,57 & 27,79 & 24,07 & 26,89 & 24,86 & 19,79 \\
\hline
\end{tabular}

Fuente: Elaboración propia a partir de datos anuales de la ECCT del MITRAMISS. 
Esta escasa dispersión porcentual entre materias evidencia que, tras responder afirmativamente a la pregunta genérica sobre si se regulan medidas de igualdad, se señalan, en la mayoría de las ocasiones, todas las materias específicas. Es posible que algunos convenios incorporen efectivamente medidas de igualdad en todas ellas, sin embargo, es muy probable que si tantas señalan todas las opciones que la hoja estadística ofrece pueda deberse a que los convenios contengan una cláusula genérica de igualdad o de prohibición de discriminación en la que se mencionen (o no) las diferentes materias. Y, sin restarle el valor que este tipo de cláusulas tiene, es evidente que no es lo mismo incluir una cláusula de este tipo que fijar medidas específicas para cada una de las materias.

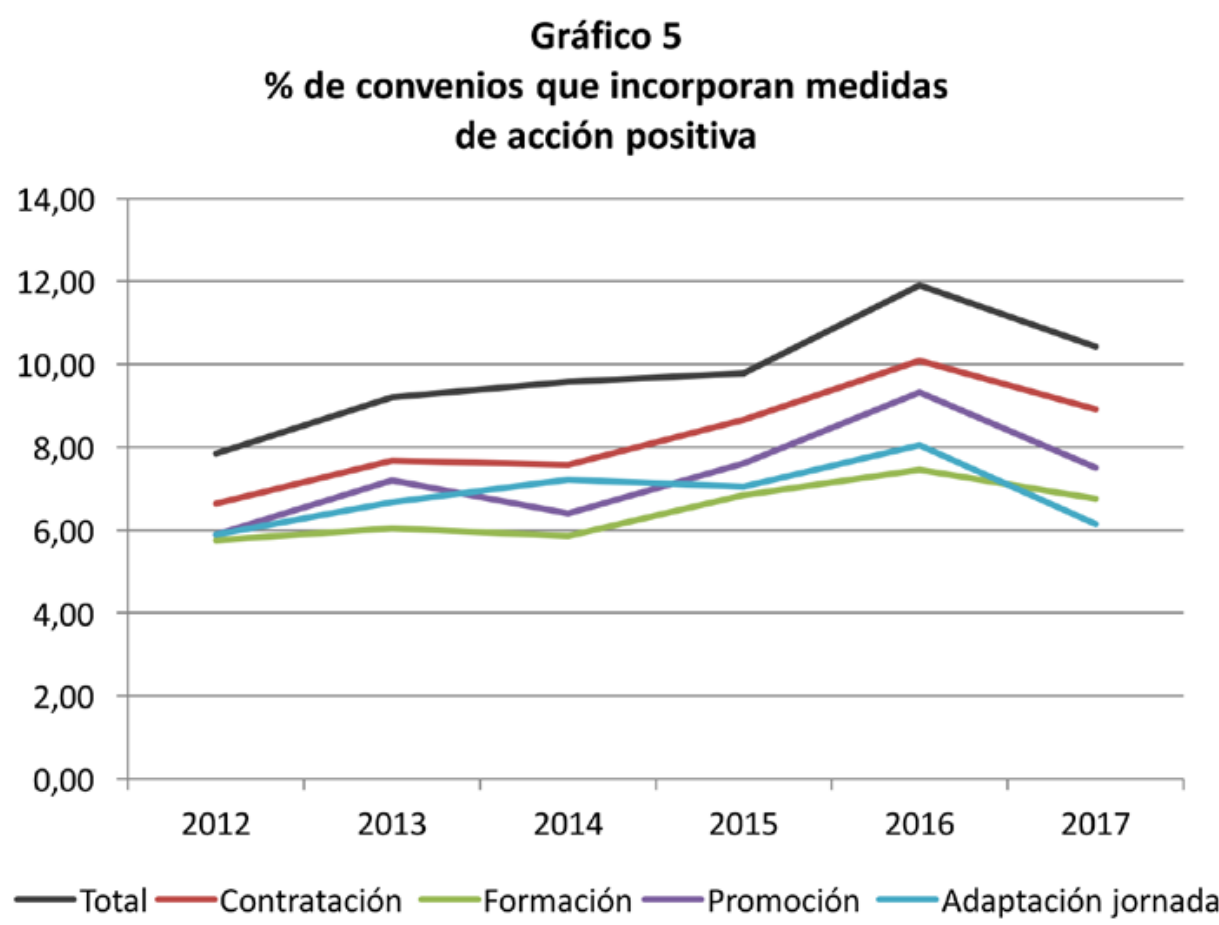

Fuente: Elaboración propia a partir de datos anuales de la ECCT del MITRAMISS.

En relación a las medidas de acción positiva ${ }^{1}$, la hoja estadística no se plantea medidas directamente dirigidas a acabar con la conocida y reconocida brecha salarial existente entre trabajadores y trabajadoras, ni para lograr una mayor estabilidad laboral de las mujeres, lo que significa que de este tipo de medidas que afortunadamente, aunque sean escasas, se establecen en algunos convenios y acuerdos, no quedaría constancia en este registro.

Entre las materias contempladas, vuelve a ser la contratación la materia que mayor proporción de medidas de acción positiva acapara, seguida por la promoción, la adaptación de la jornada laboral a la vida familiar y, por último, la formación.

\footnotetext{
${ }^{1}$ La hoja estadística se refiere a las medidas de acción positiva "a favor del sexo menos representado" siguiendo la definición contenida en el Artículo 141.4 del Tratado de Amsterdam (2 de octubre de 1997): «Con objeto de garantizar en la práctica la plena igualdad entre hombres y mujeres en la vida laboral, el principio de igualdad de trato no impedirá a ningún Estado miembro mantener o adoptar medidas que ofrezcan ventajas concretas destinadas a facilitar al sexo menos representado el ejercicio de actividades profesionales o a evitar o compensar desventajas en sus carreras profesionales".
} 
En cuanto a la dispersión de las respuestas ocurre algo similar a lo comentado con las medidas de igualdad: la horquilla en la que se mueven los porcentajes por materias de la inserción de medidas a favor del sexo menos representado es muy estrecha, oscilando entre el 7,9\% del 2012 y el 11,9\% del 2016. Y, en este caso, muy probablemente esta poca dispersión responde a una cláusula de acción positiva genérica, lo que supone la pérdida de todo el empuje con el que la ley de igualdad quería dotar a este tipo de cláusula.

\section{Gráfico 6 \\ Regulación de medidas para prevenir el acoso sexual o el acoso por razón de sexo (\%)}

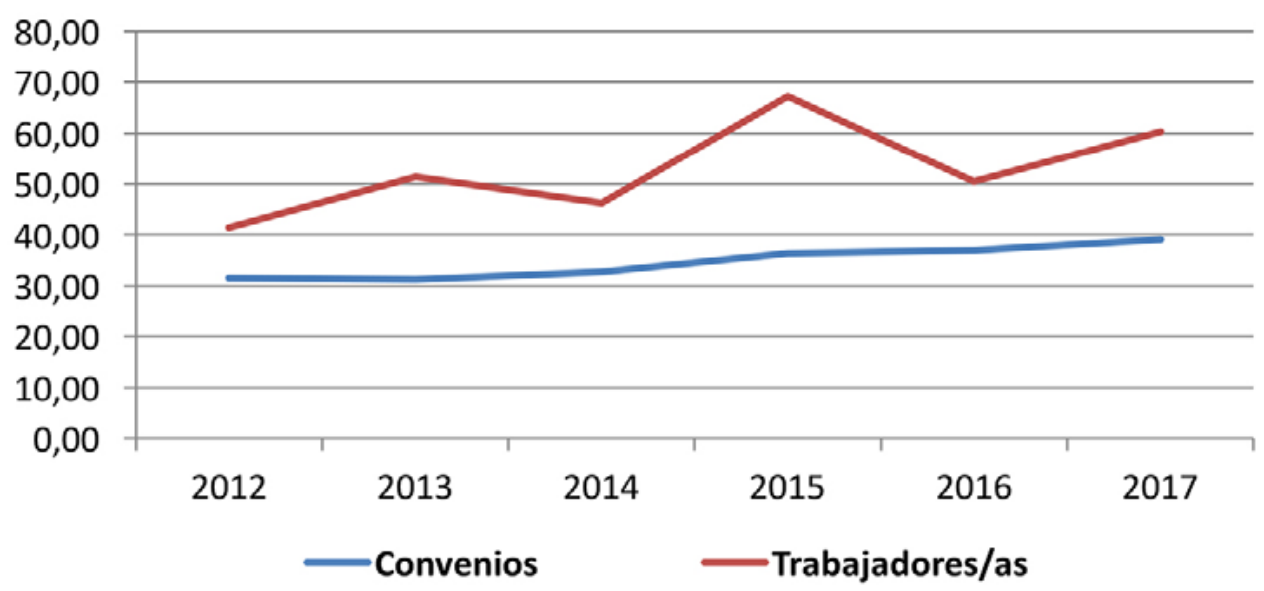

Fuente: Elaboración propia a partir de datos anuales de la ECCT del MITRAMISS.

La penúltima cuestión que la hoja estadística aborda en el apartado dedicado a la igualdad entre mujeres y hombres, se refiere al establecimiento de medidas para prevenir el acoso sexual o el acoso por razón de sexo. Una única pregunta que no permite distinguir, por ejemplo, entre medidas sobre un tipo u otro de acoso, o entre clausulas genéricas prohibitivas de este tipo de conductas, las simples referencias en la regulación de las faltas y sanciones, y acuerdos más ampliamente desarrollados dirigidos a la prevención y tratamiento de tales situaciones.

El gráfico 6 muestra unos porcentajes de inclusión de medidas de prevención del acoso sexual o por razón de sexo ciertamente significativas, en todos los años, y tanto en los convenios sectoriales como en los de empresa, por encima del 30\%. Sin embargo, y aunque es positiva la tendencia ligera pero siempre ascendente de la línea, en 2017 apenas el $40 \%$ de los convenios regulan la prevención de estos tipos de acoso, un porcentaje que no parece acorde con el alto nivel de exigencia legal en esta materia, recordemos que la Ley de Igualdad establece que: "Las empresas deberán promover condiciones de trabajo que eviten el acoso sexual y el acoso por razón de sexo y arbitrar procedimientos específicos para su prevención y para dar cauce a las denuncias o reclamaciones que puedan formular quienes hayan sido objeto del mismo". 
Finalmente, la hoja estadística vuelve a quedarse coja al preguntar sobre la regulación de medidas para la protección de las víctimas de violencia de género, una sola pregunta que no es suficiente para evaluar en qué medida los convenios se ocupan de este problema. No podemos, por tanto, distinguir entre aquellos que únicamente se hacen eco de todos o de alguno de los derechos laborales que la Ley de Protección Integral contra la Violencia de Género reconoce a las víctimas de violencia de género, de aquellos otros que consiguen pactar mejoras que les facilite superar en mejores condiciones una situación de tal vulnerabilidad.

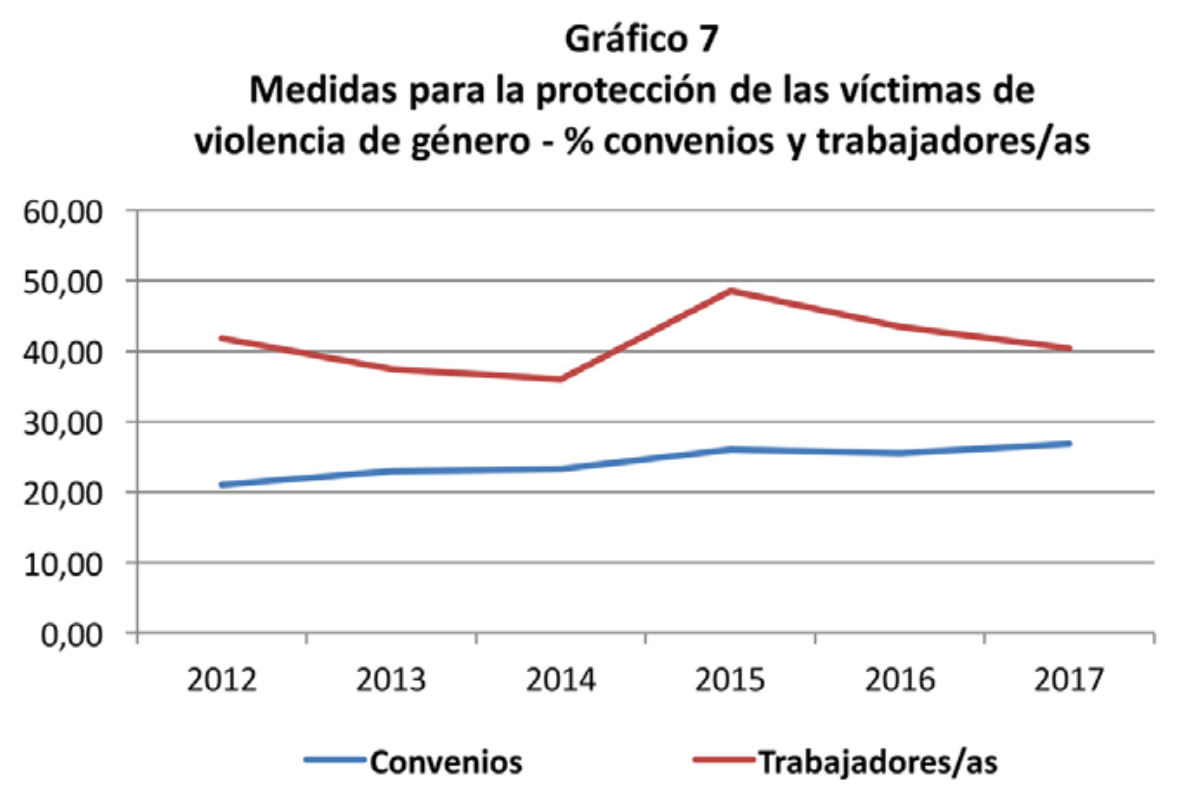

Fuente: Elaboración propia a partir de datos anuales de la ECCT del MITRAMISS.

Teniendo esto en cuenta no podemos hacer una valoración muy positiva de lo que el gráfico 7 muestra, es cierto que la evolución de la línea que representa el porcentaje de convenios que regulan estos derechos es siempre ascendente pero la progresión es muy lenta; que en 2017, doce años después de la entrada en vigor de la Ley Integral, no llegue ni al 27\% el porcentaje de convenios firmados en el año que regulen medidas de protección de las víctimas de violencia de género parece ciertamente exiguo. 